\title{
Gastric ulcer healing by cimetidine in non-Hodgkin's lymphoma of the stomach
}

\author{
M. J. BENDALL \\ B.Sc., M.B., B.S., M.R.C.P.(U.K.)
}

R. SAINSBURY*

M.B., Ch.B.(N.Z.)

\author{
Department of Health Care of the Elderly, Sherwood Hospital, Nottingham
}

\begin{abstract}
Summary
A man presented with what appeared clinically and histologically to be a benign gastric ulcer which healed with cimetidine. His condition subsequently deteriorated and a further endoscopy revealed a huge tumour in the body of the stomach with the histological appearances of non-Hodgkin's lymphoma. The presentation of non-Hodgkin's lymphoma in the elderly is discussed, together with the problem of gastriculcer healing by cimetidine in the presence of underlying malignancy.
\end{abstract}

\section{Introduction}

The use of cimetidine in the treatment of gastric ulcers is well established. Over the past three years disquiet has been expressed about the potential carcinogenicity of the drug in respect of gastric carcinoma. Most authorities believe that the carcinogenic potential though theoretically present is, in practical terms, not significant, and that what is likely to be happening is that cimetidine will heal gastric ulcers in the presence of a co-existing but initially undetected carcinoma (Leading Article, 1981).

There has also been a report (Murray et al., 1978) of a gastric ulcer healing in the presence of a lymphoma. We describe a further case of healing of a gastric ulcer with cimetidine in the presence of a nonHodgkin's lymphoma of the stomach.

\section{Case history}

A 74-year-old man presented in April 1980 with a 4-week history of epigastric pain, unrelated to food, and not accompanied by nausea or vomiting. He had been constipated for several months and his stools were black-it was presumed due to an iron preparation. He had lost about two stones in weight over a 10 -year period.

Examination revealed epigastric tenderness with minimal guarding. Haemoglobin was $13.8 \mathrm{~g} / \mathrm{dl}$, ESR

\footnotetext{
* Present address: Dr R. Sainsbury, Consultant Physician
} in Geriatric Medicine, Christchurch, New Zealand.
$41 \mathrm{~mm} / \mathrm{hr}$, WCC $11.5 \times 10^{9} /$ litre with the blood film showing a few target and burr cells. Blood urea was normal. Liver function tests revealed minor elevations of serum bilirubin and gamma glutamyl transpep- $\infty$ tidase but both subsequently returned to normal. Barium meal examination showed a large posterior $\mathbb{N}_{N}^{\infty}$ gastric ulcer with radiating mucosal folds, the folds 0 on the greater curve being rather coarse. Gastroscopy revealed a typically benign gastric ulcer, $\vec{c}$ biopsy of which showed fragments of gastric $\subsetneq$ mucosa, granulation tissue and necrotic debris heavily infiltrated with acute inflammatory cell $8 \vec{\emptyset}$ No evidence of neoplasm was seen either macre ? scopically or histologically.

Treatment was commenced with cimetidine $20 \mathrm{Q}$ $\mathrm{mg}$ each morning, $200 \mathrm{mg}$ mid-day and $400 \mathrm{mg}$ at night. By mid-July the epigastric tenderness had more or less completely subsided though he still com- $\mathbb{\Phi}$ plained of some epigastric pain. His symptoms continued to improve until by the end of November 1980 , he was symptom-free. Barium meal in September showed the ulcer to be still present but much smaller in size. A further barium meal in January 1981 showed the ulcer to have disappeared, but $\frac{0}{3}$ there were prominent irregular folds in the lower half of the body of the stomach. On previous examination, 3 the folds had been considered to be normal rugae, but they were now larger, suggesting an encephaloid $\frac{\text { 의 }}{3}$ carcinoma or a lymphosarcoma. Clinically the patient had a large hard fixed mass in the epigastrium. Gastroscopy revealed a large tumour in the $\frac{?}{0}$ body of the stomach. Histologically the appearances were of diffuse infiltration by large lymphoid cells, $N$ some of which showed plasmacytoid differentiation. There were frequent mitotic figures. The appear- $N$ ances were considered to be those of a gastric non- $\omega$ Hodgkin's lymphoma. The patient's condition deteriorated and he died next month.

Post-mortem examination showed extensive soft tumour infiltration of the posterior wall of the $\stackrel{?}{+}$ stomach with associated mucosal thickening and ulceration. The original posterior wall ulcer was $\stackrel{\mathbb{D}}{\stackrel{D}{\mathbb{N}}}$ 
completely healed. The tumour extended through the gastric wall, and there was a mass of fleshy tumour in the greater omentum and lesser sac. There was massive confluent replacement of the para-aortic, coeliac axis, gastric and porta hepatis lymph nodes with tumour.

\section{Discussion}

Clearly, as in ulceration associated with gastric carcinoma, cimetidine is able to heal gastric ulceration associated with non-Hodgkin's lymphoma. In the present case the first endoscopy indicated an apparently benign ulcer, but it seems likely that the rugal folds reported in the first barium examination represented lymphomatous infiltration, though this was not diagnosed either macroscopically or histologically at that time.

The peak incidence of non-Hodgkin's lymphoma is between the 5th and 6th decades of life (Symmers, 1978), though cases are seen at a great age. The commonest presentation of the disease is with lumps in the neck, axillae, inguinal regions or abdomen due to lymph node involvement. In a series of 123 cases of non-Hodgkin's lymphoma presenting in the elderly (age 65 years and over), $30 \%$ presented with gastro-intestinal symptoms and $20 \%$ had symptoms suggestive of carcinoma of the stomach, such as weight loss, loss of appetite and epigastric pain or discomfort (Admani, Khalequi and Mukherjee,
1981; S. K. Mukherjee, personal communication). Such symptoms are frequently found in benign gastric ulceration. Thus the present case re-emphasizes the difficulties in the diagnosis of malignancy in association with apparently benign gastric ulceration.

We also feel that the healing of this patient's ulcer by cimetidine adds weight to the argument that similar healing in the presence of a subsequently discovered gastric carcinoma does not necessarily implicate cimetidine as a carcinogen. It seems unlikely that cimetidine acts in such a way to produce a non-Hodgkin's lymphoma, and in the present case it is likely, in retrospect, that the lymphoma was the patient's underlying problem even before cimetidine therapy was commenced, and remained undetected until later.

\section{References}

Admani, A.K., Khaleque, D.M.N.F. \& Mukherjee, S.K. (1981) Study of the Clinical Presentation, Histological Classification, Management and Prognosis of non-Hodgkin's Lymphoma in the Elderly. Paper presented to XII Internation Congress of Gerontology, Hamburg, July 1981. Congress Abstracts, vol. 2, p. 281.

LEADING ARTICle (1981) 'Does cimetidine cause gastric cancer?'. British Medical Journal, 282, 1178.

Murray, C., Chapman, R., Issacson, P. \& Bamforth, J. (1978) Cimetidine and malignant gastric ulcers (letter). Lancet, i, 1092.

Symmers, Wt.St.C. (1978) In: Systemic Pathology Vol. 2. (Ed by Symmers, Wt.St.C.), pp. 768-769. Churchill Livingstone, Edinburgh. 